\title{
System of prevention of gynaecological diseases in high- productive cows under in a farm in the Udmurt Republic
}

\author{
Roman Rudakov, Liliya Khamitova*, Anastasiya Metlyakova, and Vyacheslav Milaev
}

Izhevsk State Agricultural Academy, Izhevsk 426069, Russia

\begin{abstract}
The purpose of the work is to develop a system for the restoration of the genital organs of cows after calving. We studied the therapeutic efficacy of drugs for the incidence of genital diseases of cows. The studies were conducted based on a complex of cattle of Black Motley breed at the facilities of Rico-Agro LLC in the Uvinsky district, Udmurt Republic. The average milk yield per lactation is $6250 \mathrm{~kg}$. Most animals are susceptible to ovarian disease. The incidence of ovaries hypofunction increases annually. In the study of cows on the 60th day after calving, it was found that the uterus was ready for insemination in $86 \%$ of cows. However, the condition of the ovaries allows insemination of only $50 \%$ of the cows. The remaining animals needed treatment. The most common pathology was ovarian hypofunction. This is more common in highly productive cows and cows with a low body mass index. Three regimens for treating ovaries have been tested. The most effective Scheme 2 included Surfagon and an emulsion from ASD-2 and Tetravit. In the Scheme 2 group, 6 out of 8 cows were first successfully inseminated. It was established that using Estrofan on the first day after calving, it is possible to reduce the number of persistent corpus luteum.
\end{abstract}

\section{Introduction}

To achieve a high level of animal reproduction, regular monitoring of indicators characterizing the fecundity of each animal individually and the herd as a whole is necessary. Comparison of actual and planned (optimal) indicators allows you to correctly evaluate the work of livestock breeders in reproduction, calculate the economic damage from infertility or reduce fertility and outline reasonable measures for quickly changing the state in the desired direction [4].

Currently, there are three reliable methods for diagnosing the genitals of a cow: transrectal palpation, transrectal ultrasound, and endocrine testing. Although none of them meets all the criteria for an ideal test, each has its own advantages and disadvantages. The veterinarian should carefully review each test and determine which ones are most useful for the conditions. Of these methods, transrectal palpation is the most affordable and meets most criteria in most circumstances [5].

The ovaries (ovaria) are a paired organ with generative and endocrine functions. The ovary is a dynamic organ, and its structure undergoes constant cyclic changes through the reproductive period [3].

Purpose of this work is to develop a system for the best restoration of the genitals of cows in the conditions of the economy of Rico-Agro LLC, Uvinsky District, Udmurt Republic.

To achieve this goal, the following tasks have been developed:
- To study the prevalence of genital morbidity in cows at a particular farm; (clinical and instrumental research, ultrasound)

- To study the therapeutic efficacy of hormonal drugs for the restoration of the genitals in cows

- Develop treatment and prevention regimens;

Scientific novelty. For the first time in the Udmurt Republic, using the example of the complex of RicoAgro LLC in the Uvinsky district, a comprehensive treatment regimen for recovering cows after calving was developed and tested on the basis of an individual farm study and the results of therapeutic measures.

\section{Materials and Methods}

Performing monthly gynecological medical examination of animals and analysis of the reproductive ability of females using various approaches to the restoration of animals after calving is important. So during the study period, 24 cow heads were observed from the first day after calving and until fruitful insemination. Animals are selected by the method of pairs of analogues. Animals were examined on the first day after calving for the presence of a delayed placenta and its absence, then on day 10,20 to determine the condition of the uterus. The following observation was carried out one month after calving and 60 days after calving. The condition of the uterus was monitored using an ultrasound scanner (Draminski), as well as rectal palpation of the genital organs. To study the condition of animals on the farm, they used: a retrospective, anamnestic, clinical study, including rectal examination, ultrasound of the genital 
organs. Cows were divided into groups according to the pathology of the ovaries and uterus for treatment in accordance with the scheme.

The following drugs were used for therapy: Progesterone is an oily clear solution for injection. Contains progesterone as an active ingredient $-25.0 \mathrm{mg}$. The drug has the biological effect of the natural hormone of the corpus luteum progesterone. It promotes the conversion of the endometrium from a proliferation state to a secretion state necessary for implantation and development of a fertilized egg, reduces the excitability and contractility of the muscles of the uterus and oviducts, reduces the sensitivity of the uterus to oxytocin: stimulates the development of the terminal elements of the mammary gland. Progesterone has a blocking effect on the secretion of gonadotropic releasing hormone (gonadoliberin), inhibits the formation in the pituitary gland of luteonizing and follicle-stimulating hormones. In small doses, it promotes the release of luteinizing hormone, which stimulates ovulation and development of the corpus luteum; in large doses, it delays estrus.

Surfagon is a drug whose active substance is luliberin acetate. A solution for injection, in $1 \mathrm{ml}$ as an active substance, contains $5 \mathrm{mcg}$ surfon. Competitively binds to cell receptors of the anterior pituitary gland, causing, like other GnRH analogues, a short-term increase in the level of sex hormones in the blood. The increased content of gonadotropins in the blood persists for 3-4 hours after administration, and then the content drops rapidly. The half-life of the surfer is the same as that of natural luliberin. During this time, the peptide breaks down into amino acids and is excreted from the body. Surfagon is used for early induction of the sexual cycle, treatment of hypofunction and follicular ovarian cysts, preventing early embryonic mortality, increasing the fertility of female farm animals.

ASD-2F contains a complex of biologically active substances, including low molecular weight organic compounds, including lower carboxylic acids, their amides, ammonium salts and choline esters; choline, primary and secondary amines, peptides, ammonium carbonate, ammonium acetic acid and water. It has a wide range of biological activity. ASD-2F is used for therapeutic and prophylactic purposes in diseases of the genitourinary system, metabolic disorders of various etiologies, to stimulate the activity of the central and autonomic nervous system, and to increase natural resistance in weakened animals.

Estrofan contains as an active ingredient a synthetic analogue of prostaglandin F2a (cloprostenol) - $250 \mu \mathrm{g} /$ $\mathrm{ml}$. The introduction of the drug promotes resorption of the corpus luteum and thus creates the prerequisites for the onset of estrum and ovulation. The period from the introduction of the drug to the appearance of the first signs of estrum is $48-60$ hours, the most suitable period for artificial insemination is the 76th hour from the moment of administration of the drug. The period of excretion of the drug from the body is 24 hours. It is used against synchronization and challenge of estrus in spring cows, functional disorders of the ovaries, the postpartum period and prolonged anestrus, postpartum uterine diseases, endometritis, uterine suppuration, as well as for interruption of normal and pathological pregnancy and in combination therapy of follicular cysts.

Follimag contains gonadotropin serum from mares and excipients. Issued in glass bottles of $10 \mathrm{ml}$ with hormonal activity in one bottle of $750 \mathrm{IU}$. The drug is a gonadotropin hormone (HFA) serum of mares, purified from immunogenic proteins. Gonadotropin hormone has both follicle-stimulating and luteinizing activity and does not have interspecific specificity. The drug stimulates the growth and development of follicles in female farm animals. It is used to stimulate estrum and treat ovarian hypofunction in cows.

Tetravit for animals is used to compensate for the deficiency of vitamins $\mathrm{A}, \mathrm{E}, \mathrm{D}_{3}$ and $\mathrm{F}$ in the body. Vitamin A regulates the structure, function and regeneration of epithelial tissues and thereby increases resistance against infection. Increased doses prevent weight loss and increase metabolism. Vitamin $\mathrm{D}_{3}$ regulates the exchange of calcium and phosphorus and affects their absorption in the gastrointestinal tract, has anti-rachitic effect. Vitamin E regulates redox processes and affects carbohydrate-fat metabolism, enhances the effect of vitamins $A$ and $D_{3}$. Vitamin $F$ is involved in the synthesis of fats (especially saturated ones, cholesterol metabolism, has anti-inflammatory and antihistamine effects, stimulates the body's immune defense and wound healing. In combination with vitamin $\mathrm{D}_{3}$, it assists in the assimilation of calcium and phosphorus, which is necessary for bone tissue.

\section{Results}

According to a retrospective and anamnestic study, the following results were obtained.

At the farm of Black Motley breed is kept in the number of 1646 animals. Of these, on January 1, 2019, there were 637 cows. The average milk yield of cows for 305 days of lactation is $6250 \mathrm{~kg}$. The yield of live calves per 100 cows is $85 \%$; previously this indicator did not fall below $88 \%$.

Rico-Agro is engaged in the cultivation of Blackand-White cattle for dairy. They use artificial insemination with the cervical method, using the sperm of the best bulls to produce milk, with a high proportion of fat and protein, which have categories for milk yield and mass fraction of fat. Sperm is acquired in specialized breeding companies.

Animals are kept in clean, dry and warm cowsheds with good lighting and ventilation. The cats are fat.

Cattle are kept in a stall with a paddock. Automatic milking of animals takes place in the dairy line at the site and in the milking parlour at the factory. Manure is mechanically cleaned using a scraper conveyor.

Cows are delivered to the maternity ward 10-20 days before calving. Calves are kept freely in houses. Straw and hay are used as litter in houses. Disinfection is performed after each calving, as well as in the stalls where the newborn animals are. Chemical disinfection is used after mechanical cleaning. 
Calves are kept together with their mother for up to two days. Milking is carried out using a machine in a milk line.

In summer, calves are kept in separate houses with walking paths. Animals are kept in this room for 20 to 30 days, and then moved to another room, where animals are kept for up to 6 months. Dairy calves older than 10 days are fed from buckets. In winter, calves are kept in group cells of 5-6 animals each. Garbage and manure are cleaned manually every day.

Animals up to 6 months old are kept in cells in groups of 10-15 animals each. Feeding is carried out twice a day in group feeders - a substitute for whole milk, concentrates, hay and chalk are freely available; from 3-4 months, silage is added to the diet. Next to the calf, there is a walking farm where passive physical exercises are performed. The main animals up to 6 months old move, but in winter they do not become physically active every day, because not all animals can be driven out every day in the enclosures. New-born animals receive passive movement daily.

Silage feeding is used; feeding is distributed by a mixer. Protein-mineral-vitamin-premix, additives, as well as preparations of selenium and Kayoda are also used, since the Udmurt Republic is located in a biogeochemical zone with insufficient selenium and iodine in soils and water. Feeding in winter is done twice a day. The total nutritional value of feed for dairy cows averages 21.7 feed units. In the summer grazing season, the diet of dairy cows includes: green mass, concentrates, salt and additives. For every liter of milk, $0.2 \mathrm{~kg}$ of concentrate is added to the cows. Individual drinking troughs are used for drinking. Chemical analysis of the feed gave the following results: hay and silage of the 1st, 2nd class, hay layer of the 2nd class.

In connection with increasing the productivity of animals, problems with the reproductive ability of cows begin. This is evidenced by the annual decrease in calf yield. It is also worth noting, there is a sharp jump in the disposal of cows from 10-12 to $15 \%$.

Gynaecological diseases are one of the common causes of cows dropping out of the herd for several years, they are responsible for almost a third of all causes.

A significant number of cows are prone to ovarian disease. Sick animals of different ages.

Table 1. Diagnostic results

\begin{tabular}{|l|c|c|c|c|c|}
\hline & 2015 & 2016 & 2017 & 2018 & 2019 \\
\hline $\begin{array}{l}\text { Gynecological } \\
\text { patients, total, } \\
\text { heads (\%): }\end{array}$ & $\begin{array}{c}277 \\
(100)\end{array}$ & $\begin{array}{c}298 \\
(100)\end{array}$ & $\begin{array}{c}302 \\
(100)\end{array}$ & $\begin{array}{c}372 \\
(100)\end{array}$ & $\begin{array}{c}390 \\
(100)\end{array}$ \\
\hline \multicolumn{5}{|c|}{ Including } \\
\hline $\begin{array}{l}\text { Endometritis, } \\
\text { heads (\%) }\end{array}$ & 79 & 85 & 91 & 107 & 108 \\
$(28)$ & $(29)$ & $(30)$ & $(29)$ & $(28)$ \\
\hline $\begin{array}{l}\text { Placenta retention, } \\
\text { heads (\%) }\end{array}$ & 71 & 74 & 79 & 98 & 91 \\
$(26)$ & $(25)$ & $(26)$ & $(26)$ & $(23)$ \\
\hline $\begin{array}{l}\text { Ovarian disease, } \\
\text { heads (\%) }\end{array}$ & 94 & 99 & 95 & 124 & 142 \\
$(34)$ & $(33)$ & $(32)$ & $(33)$ & $(36)$ \\
\hline $\begin{array}{l}\text { Other } \\
\text { gynaecological } \\
\text { diseases, } \\
\text { heads (\%) }\end{array}$ & 33 & 40 & 37 & 43 & 49 \\
$(12)$ & $(13)$ & $(12)$ & $(12)$ & $(13)$ \\
\hline
\end{tabular}

According to table 1, the annual growth of ovarian disease is visible. They occupy a third of all other gynaecological diseases. The most common diseases of the ovaries are ovarian hypofunction and follicular cysts (Table 2).

Table 2. Ovarian Disease Diagnostic Results

\begin{tabular}{|l|c|c|c|c|c|}
\hline \multicolumn{1}{|c|}{ Ovarian disease } & 2015 & 2016 & 2017 & 2018 & 2019 \\
\hline follicular cyst, heads & 28 & 31 & 29 & 37 & 40 \\
\hline luteal cyst, heads & 13 & 16 & 17 & 20 & 21 \\
\hline Hypofunction, heads & 26 & 25 & 26 & 38 & 46 \\
\hline Atrophy, heads & 2 & 1 & 4 & 3 & 3 \\
\hline $\begin{array}{l}\text { persistent corpus luteum, } \\
\text { heads }\end{array}$ & 21 & 26 & 19 & 26 & 32 \\
\hline
\end{tabular}

The main etiological factors that provoked the development of ovarian hypofunction are the lack of exercise in the postpartum period, and its incomplete provision, especially in the winter - stall period, as well as intensive exploitation of animals [1].

The exercise has a positive effect on the cardiovascular, respiratory, digestive, sexual and musculoskeletal systems of cows. In conditions of physical inactivity, most animals after childbirth remain with impaired sexual function and infertile [2].

According to a clinical study of animals, the following observations were made on the first day after calving: of the experimental 24 cows calving in September 2019. 11 cows left their placenta without using drugs 9 hours after calving, in 6 cows the placenta fell after applying $2 \mathrm{ml}$ of estrofan during 30 minutes after the injection, the remaining 7 cows recorded a retention of the placenta despite the use of prostaglandins.

Based on these results, we can say that with the use of estrofan 9 hours after calving, you can increase the excretion of the placenta by $25 \%$.

A rectal examination at 10, 20,30,60 days after calving revealed changes in the uterus in the observed cows.

Table 3. Results of rectal examination of cows after calving

\begin{tabular}{|l|c|c|c|c|}
\hline \multirow{2}{*}{ identified disease } & \multicolumn{5}{|c|}{ observation day } \\
\cline { 2 - 5 } & 10 & 20 & 30 & 60 \\
\hline Purulent endometritis, heads & 5 & - & - & - \\
\hline $\begin{array}{l}\text { Catarrhal purulent endometritis, } \\
\text { heads }\end{array}$ & 7 & 6 & - & - \\
\hline Uterine Subinvolution, heads & 8 & 10 & 8 & - \\
\hline Uterine atony, heads & 4 & 6 & 4 & 3 \\
\hline Norm, heads & - & 2 & 12 & 21 \\
\hline
\end{tabular}

Having examined table 3, we can conclude that by the 60th day after calving, $86 \%$ of the cows are ready for insemination according to the state of the uterus at this stage, but do not forget about the condition of the ovaries, which undergo significant changes during the recovery period after calving. So, having examined the data of obstetric-gynaecological medical examination, on the 30th and 60th day after calving, the results shown in Table 4 were obtained.

Comprehensively observing the restoration of the genital organs of a cow after calving, 12 heads were deemed ready for full-fledged estrum and fruitful 
insemination, respectively, they are being closely monitored. This is $50 \%$. The remaining cows need immediate treatment.

Hypofunction of the ovaries is accompanied by significant changes in the hormonal status of the female body. In animals, anaphrodisia is clinically manifested. A rectal examination establishes a decrease in the size of the ovaries. In heifers, they sometimes reach the size of a pea, i.e. their atrophy takes place [2].

Table 4. A diagnostic study of the condition of the ovaries in cows on days 30 and 60 after calving

\begin{tabular}{|l|c|c|}
\hline \multirow{2}{*}{ ovarian condition } & \multicolumn{2}{|c|}{ observation day after calving } \\
\cline { 2 - 3 } & 30 & 60 \\
\hline $\begin{array}{l}\text { Hypofunction: } \\
\text { one ovary, heads }\end{array}$ & 2 & 5 \\
\hline $\begin{array}{l}\text { Hypofunction: } \\
\text { two ovaries, heads }\end{array}$ & 4 & 2 \\
\hline Atrophy, heads & 1 & 1 \\
\hline $\begin{array}{l}\text { Persistent corpus luteum, } \\
\text { heads }\end{array}$ & 4 & 3 \\
\hline Luteal cyst, heads & - & 1 \\
\hline Follicular cyst, heads & - & - \\
\hline Norm, heads & 13 & 12 \\
\hline
\end{tabular}

Cows with hypofunction only on one ovary, in the presence of active estrum with vivid manifestations of all its stages, can also be inseminated without the intervention of hormonal drugs. However, cows that had hypofunction of one ovary and did not come to estrum, as well as cows that had hypofunction of two ovaries and their atrophy, needed immediate treatment.

Therefore, it was noticed that cows with ovarian hypofunction had the highest milk yield, over 35-40 litres per day, as well as low body condition. In this regard, we can conclude that highly productive cows with a low body mass index are more likely to experience ovarian disease.

Because most often ovarian hypofunction is accompanied by uterine atony, we needed to use reducing drugs to restore the uterus more quickly. Therefore, the scheme must be supplemented with a complex of drugs that reduce the uterine myometrium and restore ovarian function. So, as a reducing drug, we used Metrilong, containing propranolol in its composition. It was administered once on the first day of therapy.

Table 5. Scheme No. 1 for the restoration of ovarian function in cows

\begin{tabular}{|c|c|c|}
\hline \multirow{2}{*}{$\begin{array}{c}\text { therapy } \\
\text { day }\end{array}$} & \multicolumn{2}{|c|}{ pharmacological agent } \\
\cline { 2 - 3 } & Progesterone, $4 \mathrm{ml}$ & Surfagon, $5 \mathrm{ml}$, \\
\hline 1 & + & \\
\hline 2 & + & \\
\hline 3 & + & \\
\hline 4 & & \\
\hline 5 & & + \\
\hline 6 & & \\
\hline 7 & & \\
\hline 8 & & + \\
\hline 9 & & \\
\hline 10 & & \\
\hline
\end{tabular}

Table 6. Scheme No. 2 for the restoration of ovarian function in cows

\begin{tabular}{|c|c|c|}
\hline \multirow{2}{*}{$\begin{array}{c}\text { therapy } \\
\text { day }\end{array}$} & \multicolumn{2}{|c|}{ pharmacological agent } \\
\cline { 2 - 3 } & Surfagon, $5 \mathrm{ml}$ & $\begin{array}{c}\text { ASD-2, } \mathrm{ml} \text { tetravit } 9 \\
\mathrm{ml}\end{array}$ \\
\hline 1 & + & + \\
\hline 2 & + & + \\
\hline 3 & + & + \\
\hline 4 & & \\
\hline 5 & & \\
\hline 6 & & \\
\hline 7 & & \\
\hline 8 & & \\
\hline 9 & & \\
\hline 10 & & \\
\hline
\end{tabular}

Table 7. Scheme No. 3 for the restoration of ovarian function in cows

\begin{tabular}{|c|c|c|c|}
\hline \multirow{2}{*}{$\begin{array}{c}\text { Therapy } \\
\text { day }\end{array}$} & \multicolumn{3}{|c|}{ Pharmaceutical } \\
\cline { 2 - 4 } & $\begin{array}{c}\text { Surfagon, } \\
5 \mathrm{ml}\end{array}$ & $\begin{array}{c}\text { Estrofan, } \\
2 \mathrm{ml}\end{array}$ & $\begin{array}{c}\text { Follimag, } \\
1000,1 \mathrm{ml}\end{array}$ \\
\hline 1 & + & & \\
\hline 2 & + & & \\
\hline 3 & & & \\
\hline 4 & + & & + \\
\hline 5 & & & \\
\hline 6 & & + & \\
\hline 7 & & & \\
\hline 8 & & & \\
\hline 9 & & & \\
\hline 10 & & & \\
\hline
\end{tabular}

Based on the experimental data, one can observe the time of arrival of cows in the estrum. When analyzing these data, it turned out that the ovarian therapy had the highest quality effect on the 2 nd group of cows, in which the 2nd scheme was used, which included drugs such as surphagon and an emulsion from ASD-2 and tetravita. According to this scheme, $100 \%$ of the cows came into estrum. At the same time, the gap between days was the shortest from 5 to 12 days, and on average 7-8 days.

We would also like to note the good results obtained when using scheme 1, in which progesterone and surphagon were used $-87 \%$ of cows that came into estrum. In this scheme, the earliest occurrence in estrum for 4 days was observed for a cow 1.4, and the average rate for cows who came into estrum was 8.2 days. At the same time, there is a large and uneven variation in the period of starting the estrum, from 4 to 13 days. Therapy according to the 3 rd scheme was less successful than the others, due to the its resulting in only $66 \%$ of cows in estrum. We would also like to note the late arrival in estrum on average 9.8 days. The positive side of this scheme is a small variation in the days of coming to the hunt for 8-14 days.

2 months after the stimulation, we can conclude that the second scheme of stimulation of the sexual cycles in cows is most effective, since the highest rate of pregnant cows is 6 out of 8 , which corresponds to $75 \%$. I would also like to note $100 \%$ arrival in estrum. According to the results of Scheme 1, half of the cows inseminated once after the simulation, 2 cows re-entered the estrum, and one cow did not. Indicators of 3 stimulation schemes 
are less significant, since only 2 cows were inseminated, and 4 cows have not come to estrum at all.

Having examined the data on persistent corpus luteum, the following pattern was observed. Cows with persistent corpus luteum had no problems with delayed hatching, and accordingly they were not injected with PGF2a prostaglandins, in our case it was $2 \mathrm{ml}$ estrofan. Accordingly, we can conclude that using estrofan on the day of calving, we can significantly change the picture of persistent corpus luteum.

Using prostaglandins on the first day of calving gives us the opportunity to significantly reduce the percentage of retention of the placenta, namely by $25 \%$ according to this farm experiment. It also significantly reduces the cost of treating the retencion of the placenta and the recovery period of the cow after calving. This means that preventive measures to restore the cow after calving are the key to successful coverage of the cow for the first insemination.

\section{Conclusion}

On the farm of Rico-Agro LLC, ovarian diseases of various etiologies are widespread. The results of the studies showed that when using estrofan 9 hours after calving, the amount of placenta excretion is increased by $25 \%$. The best restoration of the ovaries with their hypofunction is observed when using a therapy regimen that includes surfagon, ASD-2, and tetravit. At the same time, $75 \%$ of the cows were inseminated from the first time. It was also found that when injecting estrofan on the first day of calving, there were no persistent yellow bodies.

\section{References}

1. L.V. Madoz, M.J. Giuliodori, A.L. Migliorisi, M. Jaureguiberry, R.L. de la Sota, Endometrial cytology, biopsy, and bacteriology for the diagnosis of subclinical endometritis in grazing dairy cows, J. Dairy Sci., 97(1), 195-201 (2014)

2. J. Stevenson, Eleven truths about ovarian cysts, Hoard's Dairyman, The National Dairy Farm Magazine, 21 (January 2012)

3. A.M. Batista, D.M. Silva, M.J. Rego, F.L. Silva, E.C. Silva, The expression and localization of leptin and its receptor in goat ovarian follicles, Anim. Reprod. Sci., 141, 142-147 (2013)

4. D. Scheetz, K.J. Forger, G.W. Smith, Granulosa cells are refractory to FSH action in individuals with a low antral follicle count, Reproduc., Fertil. and Developm., 24, 327-336 (2012) DOI: org/ 10.1071/RD11020

5. F.O. Ahmed, A.S. Elsheikh, Uterine bacterial infection during postpartum delays the recrudescence of the reproductive traits in dairy cows, J. of Americ. Sci., 9(6), 596 (2013)

6. N. Forde, M.E. Beltman, P. Lonergan, M. Diskin, J.F. Roche, Oestrous cycles in Bos Taurus cattle, Anim. Reprod. Sci., 124, 163-169 (2011)

7. D. Vuković, B. Stančić, A. Božić, Review of the dairy cows herd efficiency based on reproductive parameters, in: Proc. of 23rd Int. Symp. New technol. in contemporary animal product. (Novi Sad, Serbia, 19-21 June 2013) pp. 69-71

8. I.M. Sheldon, E.J. Williams, A.N.A. Miller, D.M. Nash, S. Herath, Uterine diseases in cattle after parturition, Veter. J., 176(1), 115-121 (2008)

9. W. Senosy, M. Uchiza, N. Tameoka, Y. Izaike, T. Osawa, Impact of ovarian and uterine conditions on some diagnostic tests output of endometritis in postpartum high-yielding dairy cows, Reproduct. in domestic anim., 46, 805 (2011)

10. F. Selami, G. Selami, Preliminary survey of the administration of $P G F 2 A$ in postpartum dairy cows, The Alban. J. of agricult. sci., 11(4), 229 (2012) 